\title{
BMJ Open Estimating the risk of cardiovascular disease using an obese-years metric
}

\author{
Asnawi Abdullah, ${ }^{1,2}$ Fauzi Ali Amin, ${ }^{3}$ Johannes Stoelwinder, ${ }^{2}$ \\ Stephanie K Tanamas, ${ }^{4}$ Rory Wolfe, ${ }^{2}$ Jan Barendregt, ${ }^{5}$ Anna Peeters ${ }^{2,4}$
}

To cite: Abdullah A, Amin FA, Stoelwinder J, et al. Estimating the risk of cardiovascular disease using an obese-years metric. $B M J$ Open 2014:4:e005629. doi:10.1136/bmjopen-2014005629

- Prepublication history for this paper is available online. To view these files please visit the journal online (http://dx.doi.org/10.1136/ bmjopen-2014-005629).

Received 5 May 2014 Revised 22 August 2014 Accepted 28 August 2014

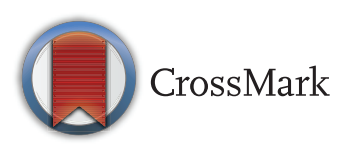

${ }^{1}$ Department of Biostatistics and Population Health, Faculty of Public Health, University Muhammadiyah Aceh, Banda Aceh, Aceh, Indonesia

${ }^{2}$ Department of Epidemiology and Preventive Medicine, School of Public Health and Preventive Medicine, Monash University, Melbourne, Victoria, Australia

${ }^{3}$ Department of Public Health Nutrition, Faculty of Public Health, University

Muhammadiyah Aceh, Banda Aceh, Aceh, Indonesia

${ }^{4}$ Baker IDI Heart and Diabetes Institute, Melbourne, Victoria, Australia

${ }^{5}$ School of Population Health, University Queensland, Herston, Queensland,

Australia

Correspondence to Dr Asnawi Abdullah; Asnawi.Abdullah@fkm. unmuha.ac.id

\section{ABSTRACT}

Objective: To examine the association between obese-years and the risk of cardiovascular disease (CVD).

Study design: Prospective cohort study. Setting: Boston, USA.

Participants: 5036 participants of the Framingham Heart Study were examined.

Methods: Obese-years was calculated by multiplying for each participant the number of body mass index (BMI) units above $29 \mathrm{~kg} / \mathrm{m}^{2}$ by the number of years lived at that BMI during approximately 50 years of follow-up. The association between obese-years and CVD was analysed using time-dependent Cox regression adjusted for potential confounders and compared with other models using the Akaike information criterion (AIC). The lowest AIC indicated better fit.

\section{Primary outcome: CVD.}

Results: The median cumulative obese-years was 24 (range 2-556 obese-years). During 138918 personyears of follow-up, $2753(55 \%)$ participants were diagnosed with CVD. The incidence rates and adjusted HR (AHR) for CVD increased with an increase in the number of obese-years. AHR for the categories 1-24.9, 25-49.9, 50-74.9 and $\geq 75$ obese-years were, respectively, 1.31 (95\% Cl 1.15 to 1.48$), 1.37(95 \% \mathrm{Cl}$ 1.14 to 1.65$), 1.62(95 \% \mathrm{Cl} 1.32$ to 1.99$)$ and 1.80 (95\% Cl 1.54 to 2.10 ) compared with those who were never obese (ie, had zero obese-years). The effect of obese-years was stronger in males than females. For every 10 unit increase in obese-years, the AHR of CVD increased by $6 \%(95 \% \mathrm{Cl} 4 \%$ to $8 \%)$ for males and $3 \%(95 \% \mathrm{Cl} 2 \%$ to $4 \%)$ for females. The AIC was lowest for the model containing obese-years compared with models containing either the level of BMI or the duration of obesity alone.

Conclusions: This study demonstrates that obeseyears metric conceptually captures the cumulative damage of obesity on body systems, and is found to provide slightly more precise estimation of the risk of CVD than the level or duration of obesity alone.

\section{BACKGROUND}

The association between obesity and cardiovascular disease (CVD) is well known. ${ }^{1}{ }^{2}$ However, these findings are generally based

\section{Strengths and limitations of this study}

- The obese-years metric combines the number of years lived with obesity and the level of body mass index (BMI) to examine the total effect of obesity.

- The Framingham Heart Study is a long-term prospective cohort study with approximately 50 years of follow-up, and biennial measurements of body weight, covariates and health outcomes.

- By using time-dependent Cox proportional hazards regression, the analysis takes into account changes in covariates during study follow-up and adjusts for a large number of potential confounding variables.

- The obese-years metric was developed based on the measurement of BMI. It is unclear whether using anthropometric measures other than BMI would produce different results.

- Data used for this study were from a relatively old cohort study, which began in 1948 .

on analysing only the level of body mass index (BMI) in relation to CVD. Recently, studies have demonstrated the importance of taking into account the potential cumulative effect of the duration of obesity, rather than the simple assessment of obesity at a single point in time (eg, at baseline). Duration of obesity has been shown to be a risk factor for CVD ${ }^{3}$ type-2 diabetes ${ }^{4}$ and mortality, ${ }^{5}$ independent of BMI. Nevertheless, analyses based on either level of BMI alone or duration lived with obesity alone, may not reflect the total effect of obesity and may underestimate the risk of CVD attributable to obesity. We have recently demonstrated the additional benefit of combining the level of obesity with the number of years lived with obesity into a single measure, finding that an obese-years metric is a better predictor of the risk of type- 2 diabetes than level of BMI or duration of obesity alone. ${ }^{6}$

The use of the obese-years metric to estimate the risk of CVD has not been investigated yet. We hypothesised that the 
obese-years metric is likely a similar independent risk factor for CVD and would provide an improved estimation of the risk of future CVD. This study aimed to examine the association between obese-years and risk of CVD and to examine whether the obese-years metric is a better predictor for risk of CVD than current BMI or duration of obesity alone. We investigated these objectives using the Framingham Heart Study (FHS), a longterm prospective cohort study where body weight, health outcomes and other covariates were measured biennially for almost 50 years. ${ }^{7}$

\section{METHODS}

Data source

We used data from the FHS. ${ }^{8}$ In this prospective cohort study, 5209 participants (aged 28-62 years at the time of enrolment) attended biennial examinations for approximately 50 years beginning from 1948 . For the purpose of this study, only participants who were free from CVD (any type), cancer and type-2 diabetes at baseline were included in the analysis $(\mathrm{n}=5036)$.

\section{Variables: measurement, missing and imputation}

Most variables in the FHS were measured regularly at the two yearly examinations, including body weight, height, demographic variables, health behaviours and health outcomes (including CVD). ${ }^{7}$ Some values are missing by design where variables were not collected at every examination. For example, current smoking status was not recorded at four examinations (2, 3, 6 and 17), cholesterol was not measured at seven examinations (11, 12, 17-20 and 22), alcohol consumption was measured only at eight examinations (2, 4, 7, 19 and 20-23), and physical activity was measured only at four examinations (4, 11,12 and 19). In this circumstance, the most contemporary measured value of the variable was used in place of missing values at the examination times when the variable was not measured. Another missing data circumstance was when missing values occurred intermittently during study follow-up; for example, body weight and hence BMI. In this case missing values for BMI were imputed with a conditional mean estimated by a multiple linear regression model using age at prior examination, sex and several transformations of the previously measured BMI (BMI, log BMI, BMI squared and BMI as a categorical variable). Methods of measurement of these variables have been described in detail elsewhere. ${ }^{46}$

\section{The level of obesity, duration and obese-years measurement}

Participants were considered obese at a given examination if their BMI was greater than or equal to $30 \mathrm{~kg} / \mathrm{m}^{2}$. The level of obesity was defined as follows: (1) if BMI $<30 \mathrm{~kg} / \mathrm{m}^{2}$, the level was zero; and (2) if BMI $\geq 30 \mathrm{~kg} / \mathrm{m}^{2}$, the level was BMI minus $29 \mathrm{~kg} / \mathrm{m}^{2}$. For example, if BMI was $35 \mathrm{~kg} / \mathrm{m}^{2}$, the level was $6(35-29)$ obese units.
The duration of obesity followed a similar definition to that described previously. ${ }^{4}$ The duration of obesity was calculated for those individuals with at least two consecutive examinations with occurrence of obesity (which is interpreted as indicating at least 2 years of being continuously obese). The requirement for two consecutive examinations with obesity was to avoid the potential misclassification of body weight, either due to measurement error or fluctuations between the borderline of the 'overweight' category or the 'obese' category. For those individuals without two consecutive obesity occurrences, duration was considered to be zero at all examinations. For those individuals with two consecutive obesity occurrences, the beginning of their obesity duration interval was defined as the date of the first of these two examinations and from that time, the individual was considered to be continuously obese until either the first of two consecutive non-obese examinations, or death, or the end of follow-up at examination 24. Individuals could have multiple periods of obesity duration during follow-up.

The level of obesity and the duration of obesity were combined as a single variable called obese-years. Obese-years was calculated at each examination as the defined level of obesity (in 'obese units') multiplied by the defined duration of obesity (in years). Then the cumulative total of obese-years for each examination was calculated as a sum of all obese-year 'exposures' up to and including that examination.

Table 1 illustrates the calculation of obese-years for a single individual. This participant first had a measurement of obesity at examination 2 and was assigned obesity duration of zero at this examination. At examination 3, this participant was assumed to have lived with obesity for 2 years (the interval between examinations 2 and 3) with a degree of obesity of $1 \mathrm{~kg} / \mathrm{m}^{2}$. This approach assumes that an individual's BMI is carried forward from a given examination (ie, examination 2) and does not change until a different BMI value at a subsequent examination (ie, examination 3 ). The number of obese-years at examination 3 was therefore 2 obese-years (1 BMI unit $\times 2$ years in the preceding interval). From examinations 3 to 4 (a 3-year interval), the participant was still obese with a degree of obesity of $3 \mathrm{~kg} / \mathrm{m}^{2}$ (BMI $32 \mathrm{~kg} / \mathrm{m}^{2}$ ). At examination 4 , the number of obese-years was 9 (3 BMI unit $\times 3$ years) and the cumulative obese-years at this examination was 11 obese-years (2 plus 9 ).

This method implies that individuals accumulating 50 obese-years, for example, could have reached this quantity either by having been obese with BMI of $30 \mathrm{~kg} / \mathrm{m}^{2}$ for approximately 50 years or by having been obese with BMI of $34 \mathrm{~kg} / \mathrm{m}^{2}$ for approximately 10 years or, indeed, many other combinations.

\section{Measurement of the outcome and time to event}

The main outcome of interest in this study was CVD incidence (the first event of any type of CVD; defined as a composite of coronary heart disease (CHD), 
Table 1 Illustration of the calculation of an obese-years metric for a single hypothetical individual

\begin{tabular}{|c|c|c|c|c|c|c|c|}
\hline ID & Examination & $\begin{array}{l}\text { Interval between } \\
\text { examinations, years* }\end{array}$ & $\begin{array}{l}\text { Body mass } \\
\text { index } \dagger\end{array}$ & $\begin{array}{l}\text { Degree of } \\
\text { obesity }\end{array}$ & $\begin{array}{l}\text { Duration of } \\
\text { obesity, years }\end{array}$ & Obese-years* & $\begin{array}{l}\text { Cumulative } \\
\text { obese-years }\end{array}$ \\
\hline 6 & 1 (baseline) & - & 28 & 0 & - & 0 & 0 \\
\hline 6 & 2 & 2 & 30 & 1 & 0 & 0 & 0 \\
\hline 6 & 3 & 2 & 32 & 3 & 2 & 2 & 2 \\
\hline 6 & 4 & 3 & 34 & 5 & 3 & 9 & 11 \\
\hline 6 & 5 & 1 & 32 & 3 & 1 & 5 & 16 \\
\hline 6 & 6 & 2 & 30 & 1 & 2 & 6 & 22 \\
\hline 6 & 7 & 1.5 & 28 & 0 & 1.5 & 1.5 & 23.5 \\
\hline 6 & 8 & 2.5 & 28 & 0 & 0 & 0 & 23.5 \\
\hline 6 & 9 & 2 & 30 & 1 & 0 & 0 & 23.5 \\
\hline 6 & 10 & 1.5 & 32 & 3 & 1.5 & 1.5 & 25 \\
\hline 6 & 11 & 3 & 34 & 5 & 3 & 9 & 34 \\
\hline 6 & 12 & 2 & 32 & 3 & 2 & 10 & 44 \\
\hline 6 & 13 & 2 & 30 & 1 & 2 & 6 & 50 \\
\hline
\end{tabular}

cerebrovascular accident (CVA), peripheral artery disease and congestive heart failure $(\mathrm{CHF})) .{ }^{9}$ Additional outcomes were individual types of CVD: hard CVD, CHD, CVA and CHF. Hard CVD was defined as a composite of hard CHD (coronary death, myocardial infarction), stroke (fatal and nonfatal), peripheral artery disease and heart failure. In the FHS, the criteria for each cardiovascular outcome during follow-up were standardised $^{10}$ and a panel of Framingham investigators made an adjudication regarding diagnosis. CHD includes the diagnoses of (1) angina pectoris, evidenced by a typical history of chest pain on a physicianadministered questionnaire; (2) myocardial infarction, determined by specified ECG changes, diagnostic elevation of serum enzymes with prolonged ischaemic chest pain, or on autopsy; (3) coronary insufficiency, defined as prolonged ischaemic chest pain accompanied by transient ischaemic abnormalities on ECG; and (4) sudden (in less than $1 \mathrm{~h}$ ) or non-sudden coronary death. CHF was indicated when at least two major or one major and two minor diagnostic conditions existed concurrently on examination.

Time to event was measured as the time from cohort entry until the date a participant was diagnosed as having CVD. Individuals who died or reached the end of the follow-up (examination 24) before developing CVD were censored at date of death or examination 24, respectively.

\section{Data analysis}

To model the relationship between the various measures of obesity and risk of CVD in a dynamic survival model way $^{11}$ an extended Cox regression model involving timedependent (time-varying) variables ${ }^{12-15}$ was used. The demographic and health behaviour variables included in the analysis were age, sex and country of birth at baseline, and the time-varying values of education level, marital status, smoking status, alcohol consumption (ounces/month) and physical activity. The regression coefficients from these models were exponentiated and interpreted as HRs noting that care is required with this interpretation $^{14}$ since the model does not technically define proportional hazards in the presence of timevarying variables.

The obese-years metric was analysed as a continuous and also as a categorical variable using the same categories used in the previous study ${ }^{6}$ for comparison purposes. For analyses of continuous obese-years, HRs are presented per 10 obese-years. For analyses of categorical obese-years, participants who were never obese during study follow-up (zero obese-years) were assigned as a comparator (reference category) and the level of obeseyears was grouped into short, medium long and extensive periods representing 1-24.9, 25-49.9, 50-74.9 and $\geq 75$ obese-years. HRs are presented as crude HRs as well as multivariate-adjusted HRs for continuous and also categorical versions of obese-years. Three models were used to examine the HRs with the addition of different confounding variables. Model 1 was adjusted for age. Model 2 was adjusted for age, sex, marital status, educational level and country of birth. Model 3 included adjustment for all variables in model 2 plus the health behaviour variables of smoking status, alcohol consumption and physical activity. The analyses were stratified by sex and a test for interaction between sex/smoking status and obese-years was performed.

To compare the relative predictive values of obesity level, obesity duration and the obese-years metric, each of these three variables was divided into an equal number of categories. One group was created for those who were never obese (BMI less than $30 \mathrm{~kg} / \mathrm{m}^{2}$ ) as a reference. For those with obesity, 10 deciles were used to create categories. The goodness of fit of the models incorporating each of the three variables was compared using Akaike's information criterion (AIC), computed as -2 (log-likelihood) +2 (number of estimated 
parameters); with a lower AIC indicating a better fit. ${ }^{16}$ All analyses were performed using the Stata statistical software package V.11.0 (StataCorp, College Station, Texas, USA). ${ }^{17}$

\section{Sensitivity analyses}

A sensitivity analysis was performed to examine whether the associations were influenced by the imputation method for missing BMI. The analysis was repeated by including only participants with no missing values of BMI at any examinations. The effect of the duration of obesity prior to baseline was tested by excluding those who were obese at baseline $(n=576)$.

\section{RESULTS}

\section{Characteristics of the participants}

Of the 5036 eligible study participants, 1230 (24\%) participants were obese for at least two consecutive examinations during the study follow-up. For those who were ever obese during the study, the median cumulative duration of obesity was approximately 12 years (range 246 years), and the median cumulative obese-years was 24 (range 2-556 obese-years). Two thousand seven hundred fifty-three $(55 \%)$ participants were diagnosed with CVD over approximately 138918 person-years of follow-up (table 2).

\section{Incidence and HRs for CVD}

The incidence rates and adjusted HR for CVD increased with an increase in the number of obese-years (tables 3 and 4). In model 3 for males and females combined, the adjusted HRs for the categories 1-24.9, 25-49.9, 5074.9 and $\geq 75$ obese-years were, respectively, 1.31 (95\% CI 1.15 to 1.48 ), 1.37 (95\% CI 1.14 to 1.65$), 1.62$ (95\% CI 1.32 to 1.99 ) and 1.80 (95\% CI 1.54 to 2.10 ) compared with those who were never obese (ie, had zero obese-years). For obese-years as a continuous variable, with every 10 unit increase in obese-years, the adjusted HR for CVD was estimated to increase by $4 \%(95 \%$ CI $3 \%$ to $5 \%$; table 5 ). There were no significant interactions between obese-year categories with sex or smoking status. There was evidence of an interaction between obese-years as a continuous variable and $\operatorname{sex}(p=0.01)$. The effect of obese-years was stronger in males than in females.

\section{Comparing obesity metrics and AIC}

Table 6 demonstrates the risk of CVD for each of the three different constructs for obesity: level of obesity (based on BMI), duration of obesity and the obese-years metric. Each construct was analysed in a separate model as an additive effect and the strength of association was compared using the AIC. In all outcomes, the AIC was lowest in the model using the obese-years metric compared with the other models for the total population and by sex.

\section{Sensitivity analysis}

The sensitivity analyses showed that the association between obese-years and risk of CVD was similar in a complete case analysis and the analysis using imputed missing values for BMI. Exclusion of participants who were obese at baseline showed only a slightly lower adjusted HR: 1.03 (95\% CI 1.01 to 1.05).

\section{DISCUSSION}

This study found that measuring the total effect of obesity by combining the level and the duration of obesity into a single metric of obese-years is a stronger predictor for the risk of CVD compared with using duration of obesity or level of obesity alone. A clear dose-response relationship between obese-years and risk of CVD was observed. A stronger effect was found in males than in females.

Although the HRs were very similar between the three different constructs, and it is not possible to perform a statistical comparison of discrimination between the models due to the fact that they are non-nested, the AIC does indicate that combining the level and duration of obesity into a single construct of obese-years provides greater discriminative power than a model with level of obesity or obesity duration alone. However, the disparity in AIC between the competing models was not as great as was observed with diabetes as the outcome of interest, ${ }^{6}$ and so it is unclear the extent to which this finding has important implications for future studies of the total health impact associated with obesity and whether future studies should take into account the impact of obesity level as well as changes in the duration of obesity.

There are different ways to operationalise the impact of excess weight over time. A recent systematic review identified at least four models: an additive model, a duration-of-obesity model, an additive-weight-change model and an interactive model. ${ }^{18}$ In addition to these models, findings using the obese-year model suggest that analysing the combined effect of the duration and the level of obesity as a predictor of CVD is worthwhile. Such approaches add information over and above simply the level of excess weight or length of time with obesity. As has been argued previously, ${ }^{6}$ other potential addition to this analysis is examining the excess body weight as higher than $25 \mathrm{~kg} / \mathrm{m}^{2}$.

The findings in this study were derived from analysis of a long-term prospective cohort study with biennial measurements of body weight, covariates and health outcomes, which enabled us to analyse change in level of obesity and duration of obesity over a long period. The analysis takes into account changes in covariates, such as smoking status, alcohol consumption and physical activity, and adjusts for a large number of potential confounding variables. However, some potential confounders, such as diet, were not collected consistently in the FHS and therefore have not been adjusted for in our analysis. 


\begin{tabular}{|c|c|c|c|c|c|c|c|c|c|c|c|c|c|}
\hline \multirow[b]{2}{*}{ Participant characteristics } & \multicolumn{3}{|c|}{ Number } & \multicolumn{3}{|c|}{ Percentage } & \multicolumn{2}{|c|}{ Median } & \multirow[b]{2}{*}{ Females } & \multicolumn{3}{|l|}{ Range } & \multirow[b]{2}{*}{ p Valuet } \\
\hline & Total & Males & Females & Total & Males & Females & Total & Males & & Total & Males & Females & \\
\hline Eligible sample & 5036 & 2237 & 2799 & 100 & 44 & 46 & & & & & & & \\
\hline Participants ever obese during study follow-up & 1247 & 494 & 750 & 24.7 & 40 & 60 & & & & & & & 0.001 \\
\hline Age at baseline (years) & & & & & & & 43 & 43 & 43 & $28-62$ & $29-62$ & $28-62$ & 0.483 \\
\hline Born in the USA & 4082 & 1826 & 2256 & 81 & 44.7 & 55.3 & & & & & & & 0.355 \\
\hline Marital status & & & & & & & & & & & & & 0.001 \\
\hline Single & 452 & 117 & 335 & 9 & 5 & 12 & & & & & & & \\
\hline Married & 4269 & 2075 & 2194 & 85 & 93 & 78 & & & & & & & \\
\hline Widowed, divorced or separated & 315 & 45 & 270 & 6 & 2 & 10 & & & & & & & \\
\hline Educational level & & & & & & & & & & & & & 0.001 \\
\hline Eighth grade or less & 1374 & 616 & 758 & 27 & 28 & 27 & & & & & & & \\
\hline High school & 2306 & 1022 & 1284 & 46 & 46 & 46 & & & & & & & \\
\hline College & 752 & 392 & 360 & 15 & 18 & 13 & & & & & & & \\
\hline Graduate school & 604 & 207 & 397 & 12 & 9 & 14 & & & & & & & \\
\hline \multicolumn{14}{|l|}{ Health behaviour } \\
\hline Current smoker at baseline & 2583 & 1435 & 1154 & 52 & 55 & 45 & & & & & & & 0.001 \\
\hline Ever-smoker during study follow-up period & 3178 & 1837 & 1341 & 63 & 58 & 42 & & & & & & & 0.001 \\
\hline Physical activity score at examination 4 & & & & & & & 32 & 33 & 31 & $25-83$ & $25-83$ & $25-55$ & 0.001 \\
\hline Alcohol drinking at examination 2, yes, ounces/month $\ddagger$ & 3183 & 1648 & 1535 & 63 & 52 & 48 & 8 & 15 & 4 & $1-360$ & $1-360$ & $1-240$ & 0.001 \\
\hline \multicolumn{14}{|l|}{ Body weight characteristics } \\
\hline Body mass index at baseline $\left(\mathrm{kg} / \mathrm{m}^{2}\right) \S$ & & & & & & & 25.1 & 25.6 & 24.6 & $16.2-46.3$ & $16.8-38.1$ & $16.2-46.3$ & 0.001 \\
\hline Underweight $(<18.5)$ & 65 & 14 & 51 & 1 & 1 & 2 & & & & & & & 0.001 \\
\hline Normal weight (18.5-24.9) & 2405 & 945 & 1460 & 48 & 42 & 52 & & & & & & & \\
\hline Overweight (25-29.9) & 1989 & 1057 & 932 & 40 & 47 & 33 & & & & & & & \\
\hline Obese $(\geq 30)$ & 567 & 217 & 350 & 11 & 10 & 13 & & & & & & & \\
\hline Cumulative obesity duration (years) & & & & & & & 12 & 10 & 12 & $2-46$ & $2-46$ & $2-46$ & 0.001 \\
\hline Cumulative obese-years ๆ & & & & & & & 24 & 15 & 31 & $2-556$ & $2-251$ & $2-556$ & 0.001 \\
\hline Cumulative obese-years category? & & & & & & & & & & & & & 0.001 \\
\hline $1-24.9$ & 579 & 269 & 319 & 52 & 62 & 45 & & & & & & & \\
\hline $25-49.9$ & 192 & 77 & 115 & 17 & 18 & 17 & & & & & & & \\
\hline $50-74.9$ & 119 & 31 & 87 & 11 & 7 & 13 & & & & & & & \\
\hline$\geq 75$ & 233 & 54 & 179 & 21 & 13 & 26 & & & & & & & \\
\hline CVD (any type) & 2753 & 1375 & 1378 & 55 & 50 & 50 & & & & & & & 0.001 \\
\hline Hard CVD & 1890 & 952 & 938 & 38 & 51 & 49 & & & & & & & 0.001 \\
\hline Coronary heart disease & 1872 & 1036 & 836 & 37 & 55 & 45 & & & & & & & 0.001 \\
\hline Heart attack & 1538 & 920 & 618 & 31 & 60 & 40 & & & & & & & 0.001 \\
\hline Myocardial infarction & 1105 & 666 & 439 & 22 & 60 & 40 & & & & & & & 0.001 \\
\hline Coronary insufficiency & 259 & 146 & 113 & 5 & 56 & 44 & & & & & & & 0.001 \\
\hline Angina pectoris & 945 & 498 & 447 & 19 & 53 & 47 & & & & & & & 0.001 \\
\hline Cerebrovascular accident & 950 & 411 & 539 & 19 & 43 & 57 & & & & & & & 0.426 \\
\hline Congestive heart failure & 876 & 397 & 479 & 17 & 45 & 55 & & & & & & & 0.556 \\
\hline $\begin{array}{l}{ }^{*} \text { Participants were free from existing diabetes, CVD and ca } \\
\text { †This p value is for the comparison of males versus femal } \\
\text { †One ounce } \approx 28.35 \mathrm{~g} . \\
\text { §Weight }(\mathrm{kg}) / \mathrm{height}(\mathrm{m})^{2} \text {. } \\
\text { TFor those who were obese during study follow-up. } \\
\text { CVD, cardiovascular disease. }\end{array}$ & $\begin{array}{l}\text { incer a } \\
\text { es. }\end{array}$ & aselin & & & & & & & & & & & \\
\hline
\end{tabular}


Table 3 Incidence of cardiovascular disease (events/ 1000 person-years) according to categories of cumulative obese-years

\begin{tabular}{lrrl}
$\begin{array}{l}\text { Obese-years } \\
\text { categories }\end{array}$ & Events & PYFU & $\begin{array}{l}\text { Incident rate } \\
\text { (95\% CI) }\end{array}$ \\
\hline $\begin{array}{l}\text { Total population, year } \\
0\end{array}$ & 2177 & 116681 & $18.66(17.89$ to 19.46$)$ \\
$1-25$ & 276 & 10846 & $25.45(22.62$ to 28.63$)$ \\
$25-50$ & 124 & 4509 & $27.50(23.06$ to 32.80$)$ \\
$50-75$ & 78 & 2365 & $32.98(26.42$ to 41.18$)$ \\
$\geq 75$ & 186 & 4517 & $41.17(35.66$ to 47.54$)$ \\
Males, year & & & \\
0 & 1138 & 46950 & $24.24(22.87$ to 25.69$)$ \\
$1-25$ & 134 & 4669 & $28.70(24.23$ to 34.00$)$ \\
$25-50$ & 56 & 1710 & $32.75(25.21$ to 42.56$)$ \\
$50-75$ & 36 & 720 & $50.02(36.08$ to 69.34$)$ \\
$\geq 75$ & 49 & 951 & $51.51(38.93$ to 68.16$)$ \\
Females, year & & & \\
0 & 1039 & 69731 & $14.90(14.02$ to 15.83$)$ \\
$1-25$ & 142 & 6177 & $22.99(19.50$ to 27.10$)$ \\
$25-50$ & 68 & 2799 & $24.30(19.16$ to 30.81$)$ \\
$50-75$ & 42 & 1645 & $25.53(18.87$ to 34.54$)$ \\
$\geq 75$ & 137 & 3566 & $38.42(32.49$ to 45.42$)$ \\
\hline PYFU, person's years of follow-up. & \\
& & &
\end{tabular}

As has been described elsewhere, ${ }^{6}$ the limitation of this analysis might relate to the population being a relatively old cohort study, the FHS that began in 1948; the prevalence rates of obesity were relatively low at that time (in the 1950 s they were below $10 \%$ ). ${ }^{19}$ It could be argued that the results of this study might not reflect contemporary populations, where the prevalence of obesity is markedly higher than 50 years ago. In 2008, the prevalence of obesity among adults in the USA was more than $30 \% .{ }^{20}{ }^{21}$ Moreover, the contemporary obesity epidemic is also characterised by a much earlier onset of obesity, which could result in even longer exposure by the time today's obese generation of children reach the age of our studied cohort. In our study, the average age at onset of obesity was approximately 50 years, and the average number of years lived with obesity was approximately 13 years; but in today's society, the average age at onset of obesity is likely to be more than 10 years earlier than in previous decades. ${ }^{22}$ Nevertheless, our results indicate that the obese-years metric is still valid and may provide more precision in predicting the risk of CVD than level of BMI or duration of obesity alone.

The obese-years metric in this study was based on the measurement of BMI. It is unclear whether using anthropometric measures other than BMI would produce different results. Although, a recent meta-analysis study has shown that BMI, waist circumference (WC) and the waist/hip ratio (WHR) each estimate a similar risk, particularly for type-2 diabetes ${ }^{23}$; it is still worthwhile to explore the relationship between obeseyears and risk of CVD using WC or WHR.

Table 4 Risk of cardiovascular disease according to categories of obese-years

\begin{tabular}{|c|c|c|c|}
\hline & \multicolumn{3}{|l|}{ HR (95\% Cl) } \\
\hline & Total population ${ }^{\star}$ & Males & Females \\
\hline \multicolumn{4}{|l|}{ Model 1} \\
\hline 0 obese-years & 1 & 1 & 1 \\
\hline $1-25$ obese-years & $1.28(1.13$ to 1.45$)$ & $1.18(0.99$ to 1.41$)$ & $1.37(1.15$ to 1.64$)$ \\
\hline 25-50 obese-years & 1.31 (1.09 to 1.57 ) & $1.28(0.97$ to 1.67$)$ & 1.40 (1.09 to 1.79$)$ \\
\hline 50-75 obese-years & 1.50 (1.21 to 1.85$)$ & 1.78 (1.35 to 2.36$)$ & 1.46 (1.08 to 1.96$)$ \\
\hline$\geq 75$ obese-years & 1.59 (1.36 to 1.85$)$ & 1.72 (1.33 to 2.22$)$ & 1.78 (1.48 to 2.15$)$ \\
\hline Dose-response $p$ value & 0.001 & 0.001 & 0.001 \\
\hline \multicolumn{4}{|l|}{ Model 2} \\
\hline 0 obese-years & 1 & 1 & 1 \\
\hline 1-25 obese-years & $1.26(1.11$ to 1.43$)$ & $1.18(0.99$ to 1.41$)$ & $1.33(1.11$ to 1.60$)$ \\
\hline 25-50 obese-years & 1.32 (1.10 to 1.59$)$ & 1.29 (0.99 to 1.70$)$ & 1.35 (1.05 to 1.74$)$ \\
\hline 50-75 obese-years & 1.55 (1.27 to 1.91$)$ & 1.80 (1.36 to 2.38$)$ & $1.40(1.04$ to 1.88$)$ \\
\hline$\geq 75$ obese-years & 1.74 (1.50 to 2.03$)$ & 1.71 (1.32 to 2.21$)$ & 1.71 (1.42 to 2.07 ) \\
\hline Dose-response $p$ value & 0.001 & 0.001 & 0.001 \\
\hline \multicolumn{4}{|l|}{ Model 3} \\
\hline 0 obese-years & 1 & 1 & 1 \\
\hline 1-25 obese-years & $1.31(1.15$ to 1.48$)$ & $1.22(1.02$ to 1.45$)$ & $1.37(1.14$ to 1.65$)$ \\
\hline 25-50 obese-years & $1.37(1.14$ to 1.65$)$ & 1.39 (1.05 to 1.83$)$ & $1.36(1.05$ to 1.76$)$ \\
\hline 50-75 obese-years & $1.62(1.32$ to 1.99$)$ & 1.89 (1.42 to 2.51$)$ & $1.44(1.08$ to 1.94$)$ \\
\hline$\geq 75$ obese-years & 1.80 (1.54 to 2.10$)$ & 1.81 (1.39 to 2.36$)$ & $1.74(1.44$ to 2.10$)$ \\
\hline Dose-response $p$ value & 0.001 & 0.001 & 0.001 \\
\hline
\end{tabular}


Table 5 The HR of CVD per 10 obese-years

\begin{tabular}{|c|c|c|c|}
\hline \multirow[b]{2}{*}{ CVD } & \multicolumn{3}{|c|}{ HR per additional 10 obese-years ( $95 \% \mathrm{CI})$} \\
\hline & Total population* & Males & Females \\
\hline \multicolumn{4}{|c|}{ CVDs (all types) } \\
\hline Model 1 & $1.03(1.02$ to 1.04$)$ & 1.05 (1.03 to 1.07$)$ & $1.03(1.02$ to 1.04$)$ \\
\hline Model 2 & 1.03 (1.02 to 1.04$)$ & 1.05 (1.03 to 1.07$)$ & $1.03(1.02$ to 1.04$)$ \\
\hline Model 3 & $1.04(1.03$ to 1.05$)$ & $1.06(1.04$ to 1.08$)$ & $1.03(1.02$ to 1.04$)$ \\
\hline \multicolumn{4}{|l|}{ Hard CVDs } \\
\hline Model 1 & $1.03(1.02$ to 1.04$)$ & $1.06(1.04$ to 1.08$)$ & $1.03(1.02$ to 1.05$)$ \\
\hline Model 2 & $1.04(1.03$ to 1.05$)$ & $1.06(1.04$ to 1.08$)$ & $1.03(1.02$ to 1.04$)$ \\
\hline Model 3 & 1.04 (1.03 to 1.05$)$ & 1.06 (1.04 to 1.08$)$ & $1.03(1.02$ to 1.04$)$ \\
\hline \multicolumn{4}{|l|}{$\mathrm{CHD}$} \\
\hline Model 1 & $1.02(1.01$ to 1.03$)$ & $1.03(1.01$ to 1.06$)$ & $1.03(1.02$ to 1.04$)$ \\
\hline Model 2 & $1.03(1.02$ to 1.04$)$ & $1.03(1.01$ to 1.06$)$ & $1.03(1.02$ to 1.04$)$ \\
\hline Model 3 & $1.03(1.02$ to 1.04$)$ & $1.04(1.02$ to 1.06$)$ & $1.03(1.02$ to 1.04$)$ \\
\hline \multicolumn{4}{|l|}{ CVA } \\
\hline Model 1 & $1.03(1.02$ to 1.04$)$ & $1.06(1.04$ to 1.09$)$ & $1.03(1.01$ to 1.04$)$ \\
\hline Model 2 & $1.03(1.02$ to 1.04$)$ & 1.06 (1.04 to 1.09$)$ & $1.02(1.01$ to 1.04$)$ \\
\hline Model 3 & 1.03 (1.02 to 1.04$)$ & 1.06 (1.04 to 1.09$)$ & $1.02(1.01$ to 1.04$)$ \\
\hline \multicolumn{4}{|c|}{ Congestive heart failure (CHF) } \\
\hline Model 1 & $1.05(1.03$ to 1.06$)$ & 1.06 (1.04 to 1.09$)$ & $1.05(1.03$ to 1.06$)$ \\
\hline Model 2 & 1.05 (1.04 to 1.06$)$ & 1.06 (1.04 to 1.09$)$ & $1.04(1.03$ to 1.06$)$ \\
\hline Model 3 & 1.05 (1.04 to 1.06$)$ & 1.06 (1.04 to 1.09$)$ & $1.04(1.03$ to 1.06$)$ \\
\hline
\end{tabular}

Model 1 adjusted for age.

Model 2 adjusted for age, marital status, education and country of birth.

Model 3 adjusted for age, marital status, education, country of birth, smoking status, alcohol consumption and physical activity.

*For total population also adjusted for sex

CHD, coronary heart disease; CVA, cerebrovascular accident; CVD, cardiovascular disease.

Table 6 Comparison of the obese-years metric, BMI and obesity duration as predictors of the risk for CVD

\begin{tabular}{|c|c|c|c|}
\hline \multirow[b]{2}{*}{ Constructs } & \multicolumn{3}{|l|}{ AIC } \\
\hline & Total population & Males & Females \\
\hline \multicolumn{4}{|l|}{ CVDs (all types) } \\
\hline Construct 1: level of BMI & 43390 & 19227 & 20307 \\
\hline Construct 2: duration of obesity & 43379 & 19221 & 20306 \\
\hline Construct 3: obese-years & 43368 & 19209 & 20294 \\
\hline \multicolumn{4}{|l|}{ Hard CVDs } \\
\hline Construct 1: level of BMI & 34069 & 15102 & 15976 \\
\hline Construct 2: duration of obesity & 34065 & 15099 & 15968 \\
\hline Construct 3: obese-years & 34050 & 15096 & 15955 \\
\hline \multicolumn{4}{|l|}{$\mathrm{CHD}$} \\
\hline Construct 1: level of BMI & 29038 & 14355 & 12156 \\
\hline Construct 2: duration of obesity & 29039 & 14354 & 12162 \\
\hline Construct 3: obese-years & 29028 & 14351 & 12152 \\
\hline \multicolumn{4}{|l|}{ CVA } \\
\hline Construct 1: level of BMI & 13575 & 5211 & 7147 \\
\hline Construct 2: duration of obesity & 13577 & 5208 & 7141 \\
\hline Construct 3: obese-years & 13573 & 5208 & 7136 \\
\hline \multicolumn{4}{|l|}{ Congestive health failure (CHF) } \\
\hline Construct 1: level of BMI & 13141 & 5275 & 6667 \\
\hline Construct 2: duration of obesity & 13122 & 5263 & 6663 \\
\hline Construct 3: obese-years & 13104 & 5255 & 6649 \\
\hline \multicolumn{4}{|c|}{$\begin{array}{l}\text { Each construct was split into } 11 \text { categories; } 1 \text { represents 'not obese' and } 2-11 \text { represent deciles of obesity exposure (level, duration and } \\
\text { obese-years). } \\
\text { Each model adjusted for sex, age, marital status, education, smoking, alcohol consumption and physical activity. } \\
\text { AIC, Akaike information criterion; BMI, body mass index; CHD, coronary heart disease; CVA, cerebrovascular accident; CVD, cardiovascular } \\
\text { disease }\end{array}$} \\
\hline
\end{tabular}


As discussed in our previous study, ${ }^{6}$ the obese-years metric was developed based on the assumption that level and duration of obesity have a similar impact, an assumption that has been used for the concept of packyears in smoking studies. In some smoking studies, it was highlighted that for certain health outcomes, the effect of the duration was more important than intensity, ${ }^{24}$ while in others, duration was not significant after adjustment for intensity. ${ }^{25}$ As we have previously discussed, the notion that obese-years is only 'switched on' when BMI reaches $30 \mathrm{~kg} / \mathrm{m}^{2}$ is crude, ${ }^{6}$ however, it is an important construct to consider whether the combination of level and duration is relevant for a particular outcome. In addition, although obese-years do find a parallel in packyears for smoking, which is a construct that ignores any effects of passive smoking, the nature of cumulative exposure in obesity is not as straightforward as in smoking.

These findings demonstrate that it is important to consider the level of obesity as well as the duration of obesity and their combination when examining the association between obesity and the risk of chronic disease. This effect is likely to be because the obese-years metric takes into account the cumulative damage of obesity to body systems and consequently is likely to be applicable to other chronic diseases. However, further investigations are recommended to be undertaken, of other possible level/duration constructs of obesity such as considering the effect of BMI above $25 \mathrm{~kg} / \mathrm{m}^{2}$, and of relationships between obese-years and other chronic diseases, and mortality.

We acknowledge that a major challenge in examining the obese-years metric is to have information on the degree of obesity and the duration of obesity. Few cohort studies measure obesity and health outcomes regularly as in the FHS. However, we believe there would be value in more detailed assessment of height and weight on multiple repeated occasions in future cohort studies and to identify other more readily available proxies of duration, such as peak weight or age of onset of obesity, and to test to what extent those variables are equivalent to the obese-year metric.

It is important that these results inform future epidemiological analyses, suggesting that the risk of obesity on some health outcomes is being underestimated if duration is not being taken into account. This has consequent implications for underestimation of obesity-related burden of disease modelling and cost-effectiveness analyses. In addition, the results inform public health policy, demonstrating further rationale for preventing weight gain and delaying the onset of obesity.

\section{CONCLUSION}

This study demonstrates that the risk of CVD associated with obesity is derived from the level of obesity attained and also the length of time lived with obesity. The obeseyears metric conceptually captures the cumulative damage of obesity on body systems, and is found to provide slightly more precise estimation of the risk of CVD than the level or duration of obesity alone.

Acknowledgements The authors thank the Framingham Heart Study investigators for granting them permission to use their data set for this study (the Framingham Heart Study is conducted and supported by the National Heart, Lung, and Blood Institute (NHLBI) in collaboration with study investigators). This manuscript was prepared by using a limited-access data set obtained from the NHLBI.

Contributors Author AA developed the analytical techniques of study, performed data analysis, interpretation, drafting of the manuscript and prepared the final version for publication. FAA performed data analysis and interpretation of data. JS, SKT and JB helped review the data analysis and reviewed the manuscript. RW contributed to the study design and review of the manuscript. AP supervised the implementation of the study, designed the study's analytic strategy and contributed to the reviewing of the manuscript.

Funding This research received no specific grant from any funding agency in the public, commercial or not-for-profit sectors.

Competing interests $A A$ and FAA were supported by an Indonesian Danone institutional research grant 2012. AP and SKT were supported by an NHMRC project grant.

Ethics approval Syiah Kuala University Research Ethics Committee.

Provenance and peer review Not commissioned; externally peer reviewed.

Data sharing statement No additional data are available.

Open Access This is an Open Access article distributed in accordance with the Creative Commons Attribution Non Commercial (CC BY-NC 4.0) license, which permits others to distribute, remix, adapt, build upon this work noncommercially, and license their derivative works on different terms, provided the original work is properly cited and the use is non-commercial. See: http:// creativecommons.org/licenses/by-nc/4.0/

\section{REFERENCES}

1. Hubert HB, Feinleib M, McNamara PM, et al. Obesity as an independent risk factor for cardiovascular disease: a 26-year follow-up of participants in the Framingham Heart Study. Circulation 1983;67:968-77.

2. Morrison JA. Obesity and cardiovascular disease risk factors in Black and White girls: the NHLBI Growth and Health Study. Am J Public Health 1992;82:1613-20.

3. Abdullah A, Stoelwinder A, De Courten M, et al. The duration of obesity and the risk of cardiovascular disease. The Conference on Clinical Epidemiology and Evidence-Based Medicine in Global Perspective 27-28 November. Bali, Indonesia, 2010.

4. Abdullah A, Stoelwinder J, Shortreed S, et al. The duration of obesity and the risk of type 2 diabetes. Public Health Nutr 2011;14:119-26.

5. Abdullah A, Wolfe R, Stoelwinder JU, et al. The number of years lived with obesity and the risk of all-cause and cause-specific mortality. Int J Epidemiol 2011;40:985-96.

6. Abdullah A, Wolfe $\mathrm{R}$, Mannan $\mathrm{H}$, et al. Epidemiologic merit of obese-years, the combination of degree and duration of obesity. Am J Epidemiol 2012;176:99-107.

7. Dawber T. The Framingham study: the epidemiology of atherosclerotic disease. Cambridge, Massachusetts: Harvard University Press, 1980.

8. National Heart, Lung, and Blood Institute, Boston University. The Framingham Heart Study: 50 years of research success. Framingham, MA: Framingham Heart Study, 2012. http://www.nhlbi. nih.gov/about/framingham/index.html (accessed 5 Nov 2012).

9. D'Agostino RB Sr, Vasan RS, Pencina MJ, et al. General cardiovascular risk profile for use in primary care: the Framingham Heart Study. Circulation 2008;117:743-53.

10. Wilson PWF, D'Agostino RB, Sullivan L, et al. Overweight and obesity as determinants of cardiovascular risk: the Framingham experience. Arch Intern Med 2002;162:1867-72.

11. He J, McGee D, Niu X, et al. Examining the dynamic association of $\mathrm{BMI}$ and mortality in the Framingham Heart Study. Int J Environ Res Public Health 2009;6:3115-26.

12. Parmar MKB, Machin D. Survival analysis : a practical approach. Chichester; New York: J. Wiley, 1995. 
13. Fisher LD, Lin DY. Time-dependent covariates in the Cox Proportional-Hazards Regression Model. Annu Rev Public Health 1999;20:145-57.

14. Kleinbaum DG, Klein M. Survival analysis: a self-learning text. USA Springer, 2005.

15. Cleophas TJM, Zwinderman AH. Machine learning in medicine. Dordrecht: Springer, 2013.

16. Akaike $\mathrm{H}$. A new look at the statistical model identification. IEEE Trans Automatic Control 1974;19:716-23.

17. StataCorp LP. Stata Survival Analysis and Epidemiological Tables Reference Manual Release 10. College Station, TX: Stata Corporation, 2007.

18. Preston SH, Mehta NK, Stokes A. Modeling obesity histories in cohort analyses of health and mortality. Epidemiology 2013;24:158-66.

19. National Center for Health Statistics National HaNESH, MD: National Center for Health Statistics. http://www.cdc.gov/nchs/nhanes.htm (accessed 3 Nov 2002). Secondary.
20. CDC. State-specific prevalence of obesity among adults-United States. MMWR 2008;57:765-8.

21. World Health Organization. Global database on body mass index. Secondary global database on body mass index 2014. http://apps. who.int/bmi/index.jsp

22. Lee JM, Pilli S, Gebremariam A, et al. Getting heavier, younger: trajectories of obesity over the life course. Int J Obes (Lond) 2010;34:614-23.

23. Vazquez G, Duval S, Jacobs DR Jr, et al. Comparison of body mass index, waist circumference, and waist/hip ratio in predicting incident diabetes: a meta-analysis. Epidemiol Rev 2007;29:115-28.

24. Lagergren J, Bergström R, Lindgren A, et al. The role of tobacco, snuff and alcohol use in the aetiology of cancer of the oesophagus and gastric cardia. Int $J$ Cancer 2000;85:340-6.

25. Yuan JM, Wang XL, Xiang YB, et al. Non-dietary risk factors for nasopharyngeal carcinoma in Shanghai, China. Int $J$ Cancer 2000;85:364-9. 